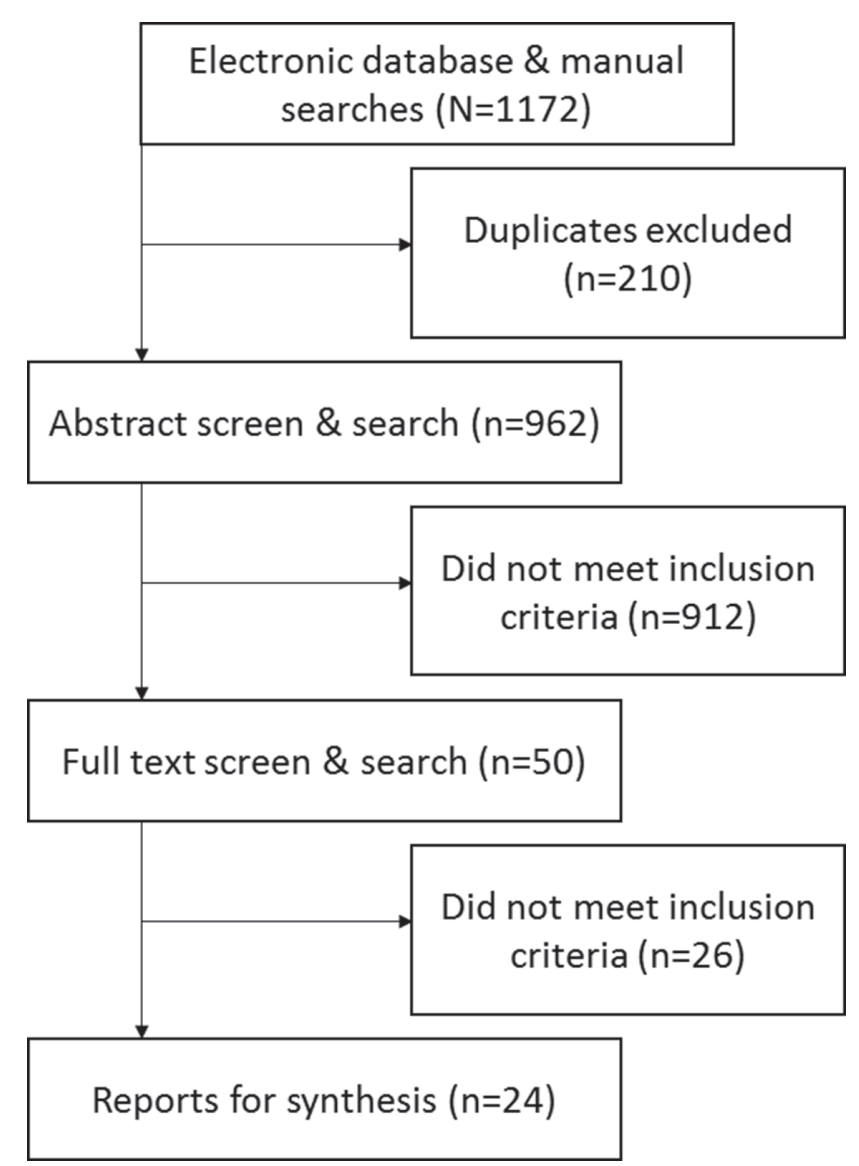

Abstract P163 Figure 1 PRISMA flow diagram of evidence synthesis

\section{P164 CHANGING PATTERNS OF THE USE OF LUNG BIOPSY IN INTERSTITIAL LUNG DISEASE}

L Brockbank, E Hilal, J Holemans, J Greenwood, M Walshaw, K Mohan. Liverpool Heart and Chest Hospital, Liverpool, UK

\subsection{6/thoraxjnl-2016-209333.307}

Introduction Radiological and international guidelines have improved the diagnosis of interstitial lung disease (ILD) subtype in the absence of a surgical lung biopsy (SBX). However, it may still be needed since up to $38 \%$ of cases ${ }^{1}$ cannot be diagnosed on clinical and radiological grounds alone, and new antifibrotic therapies require more diagnostic certainty for idiopathic pulmonary fibrosis (IPF). We wished to ascertain whether SBx rates and diagnostic outcomes had changed at our regional thoracic centre. Methods We looked at 104 consecutive patients undergoing SBx between May 2014 to April 2016, and compared their mode of referral and outcome with a previous study (210 cases) in the same centre conducted between 2001 and 2008.

Results There was no evidence of multidisciplinary team (MDT) input prior to SBx in 31 cases $(30 \%)$, but 18 (17\%) were discussed at an ILD MDT and 55 (53\%) in local radiology meetings. For SBx outcome see Table. Prior diagnosis was uncertain in $28 \%$ of ILD MDT cases and $27 \%$ of local radiology meeting cases, whereas SBx confirmed the suspected diagnosis in 22\% of ILD MDT cases but only $9 \%$ of radiology meeting cases.
Conclusion Overall, there appears to be increase in the ILD cases referred for SBx. Despite the small proportion of cases discussed at the ILD MDT prior to SBx, there appears to be a trend in the reduction of UIP/NSIP and significant increase in HSP, RBILD and DIP cases. Histological diagnosis remains important in ILD, and the use of other techniques with lower complication rates (e. g. transbronchial cryobiopsy) needs to be established.

\begin{tabular}{|c|c|c|c|}
\hline Diagnosis & $\begin{array}{l}\text { Percentage of cases } \\
2001-2008(n=210)\end{array}$ & $\begin{array}{l}\text { Percentage of cases } \\
2014-2016(n=104)\end{array}$ & $P=$ \\
\hline $\begin{array}{l}\text { Usual interstitial } \\
\text { pneumonia (UIP) }\end{array}$ & $37 \%$ & $29 \%$ & 0.17 \\
\hline $\begin{array}{l}\text { Non-specific interstitial } \\
\text { pneumonia (NSIP) }\end{array}$ & $12 \%$ & $7 \%$ & 0.17 \\
\hline Organising pneumonia & $10 \%$ & $3 \%$ & 0.025 \\
\hline Sarcoidosis & $8 \%$ & $10 \%$ & 0.53 \\
\hline $\begin{array}{l}\text { Smoking related (RB-ILD, } \\
\text { DIP) }\end{array}$ & $9 \%$ & $23 \%$ & 0.0014 \\
\hline $\begin{array}{l}\text { Hypersensitivity } \\
\text { pneumonitis }\end{array}$ & $4 \%$ & $12 \%$ & 0.0072 \\
\hline $\begin{array}{l}\text { Vasculitis/Connective } \\
\text { tissue disease }\end{array}$ & $2 \%$ & $1 \%$ & $>0.99$ \\
\hline Other & $18 \%$ & $15 \%$ & 0.43 \\
\hline
\end{tabular}

\section{REFERENCE}

1 Raghu G, Mageto YN, Lockhart D, et al. The accuracy of the clinical diagnosis of new-onset idiopathic pulmonary fibrosis and other interstitial lung disease. A prospective study. Chest 1999;116:1168-1174.

\section{P165 SURGICAL LUNG BIOPSY IN THE DIAGNOSIS OF INTERSTITIAL LUNG DISEASE - WHERE ARE WE NOW?}

L Brockbank, E Hilal, L Johns, M Walshaw, K Mohan. Liverpool Heart and Chest Hospital, Liverpool, UK

\subsection{6/thoraxjnl-2016-209333.308}

Introduction With the advent of multidisciplinary team (MDT) working and new therapies in interstitial lung disease (ILD), diagnostic accuracy is increasingly important, and international guidelines ${ }^{1}$ have reaffirmed the importance of surgical lung biopsy (SBx) where necessary. However, SBx has associated risks: to assess this further we looked at the diagnostic yield and complication rate of SBx carried out at our regional thoracic centre for patients with ILD.

Methods We looked at all 104 SBxs carried out for ILD over 24 months between 2014-16, collecting data on the nature of the procedure, number of lobes sampled, complications encountered and mortality, and also whether the cases had been discussed at a regional ILD or local radiology MDT meeting prior to SBx.

Results Seventy cases (67\%) had been discussed prior to SBx (18 at an ILD MDT). Overall, mean age was 56 years, mean FEV1 $79 \%$ predicted, FVC $84 \%$ predicted, RV $79 \%$ predicted, TLC $77 \%$ predicted, TLCO $56 \%$ predicted, and KCO 77\% predicted. All but 3 procedures were carried out by VAT: the median number of lobes sampled was 2 (>1 lobe in $86 \%$ ), and diagnostic specimens were obtained in 97\% (UIP 29\%, RB-ILD and DIP $23 \%$, HSP $12 \%$, Sarcoid 10\%, NSIP 7\%, others 19\%). For complications see Table. The mean length of stay was 5.2 days (range 1-44): in-hospital mortality and 30-day mortality were $1 \%$ and $3 \%$ respectively. 